\title{
VISITAÇÃO DE Buddleja brasiliensis (BUDDLEJACEAE) POR ABELHAS E BEIJA-FLORES EM MATA HIGRÓFILA DE PLANALTO PAULISTA
}

Rodolfo Antônio de Figueiredo

PG-Ecologia, Instituto de Biologia, Departamento de Botânica

UNICAMP - Campinas, SP

\section{RESUMO}

A polinização de Buddleja brasiliensis é realizada por beijaflores de pequeno porte na Mata Atlântica. Este estudo objetivou verificar se essas aves também eram os principais visitantes da espécie vegetal em mata de planalto paulista. As observações de visitantes florais foram feitas na Reserva de Santa Genebra, Campinas (SP), entre às $6 \mathrm{~h}$ e 18h. Os beijaflores Chlorostilbon aureoventris e Thalurania glaucopis visitaram as inflorescências, mas os visitantes mais freqüentes foram abelhas Apidae e Anthophoridae. Estes resultados indicam que as flores de B. brasiliensis, apesar de serem visitadas por beija-flores de pequeno porte, são mais utilizadas por abelhas em mata higrófila.

\section{SUMMARY}

Figueiredo, R.A.de. Visitation of Buddleja brasiliensis (Buddlejaceae) by bees and hummingbirds in an upland hygrophilous forest of São Paulo State. 
The pollination of Buddleja brasiliensis in the Atlantic rainforest is carried out by small hummingbirds. This study intended to verify if these birds are also the main visitors at this plant species in an upland forest of São Paulo State. Observations on floral visitors were done at the Reserva de Santa Genebra, Campinas, between 6:00am and 6:00pm (24 hours total). The hummingbirds Chlorostilbon aureoventris and Thalurania glaucopis visited the inflorescences, but the most frequent visitants were Apidae and Anthophoridae bees. These results indicate that the flowers of $B$. brasiliensis, although being visited by small hummingbirds, are utilized mainly by bees in hygrophilous forests.

\section{INTRODUÇÃO}

Beija-flores são os mais importantes vertebrados polinizadores neotropicais e, das 320 espécies existentes, 86 ocorrem no Brasil ${ }^{1,2,3}$. Apesar da importância destas aves em diversas comunidades, existem ainda poucos estudos brasileiros sobre as interações de beija-flores com plantas ornitófilas $4,5,6,7,8,9,10,11$

As plantas que apresentam flores típicas da síndrome da ornitofilia e os beija-flores são tidos como parceiros de uma ajustada coevolução, na qual as espécies envolvidas se adaptaram umas às outras 12,13. Porém, atributos morfológicos e comportamentais destas aves influenciam a sua estratégia de forrageamento ${ }^{14,15,16}$, assim como as relações entre as diversas espécies de beija-flores que ocorrem em uma determinada área podem influir no número e nos taxa dos recursos florais utilizados por cada espécie ${ }^{17}$.

Em áreas montanhosas de Mata Atlântica no sudeste brasileiro, verificou-se que Buddleja brasiliensis é visitada principalmente por beija-flores de pequeno porte, principalmente Stephanoxis lalandi e Calliphlox amethystina ${ }^{18,19}$. Esses beija-flores visitavam as flores do vegetal durante todo o dia a intervalos regulares e foram considerados polinizadores 
efetivos ${ }^{18}$. Outros visitantes, tais como abelhas e borboletas foram muito $\operatorname{raros}^{19}$.

O objetivo do presente estudo foi verificar se esta planta é visitada principalmente por beija-flores também em uma mata higrófila de planalto paulista.

\section{MATERIAL E MÉTODOS}

A família Buddlejaceae (Tubiflorae) apresenta flores pequenas, hermafroditas e de simetria zigomorfa ${ }^{20}$. O gênero mais comum é Buddleja, com espécies ruderais e algumas utilizadas como ornamentais ${ }^{21}$. Buddleja brasiliensis floresce de maio a agosto na área de estudo e apresenta inflorescências com flores amarelas tubulares (ca. $10 \mathrm{~mm}$ de comprimento). A antese se dá seqüencialmente da parte proximal à distal da inflorescência, apresentando algumas dezenas de flores receptivas a cada dia.

As observações de campo foram realizadas no mês de julho, quando foi registrada temperatura média de $19^{\circ} \mathrm{C}$ e $80 \mathrm{~mm}$ de precipitação pluviométrica, em uma área de mata higrófila (também denominada mata de brejo) da Reserva de Santa Genebra (22 $44^{\prime} 45^{\prime \prime} S, 47^{\circ} 06^{\prime} 33^{\prime \prime W}, 670 \mathrm{~m}$ alt.). Esta reserva é um fragmento florestal de 251,77 ha composto por matas semidecíduas e higrófilas ${ }^{22}$. A área apresenta clima tropical sazonal, com precipitação anual de $1360 \mathrm{~mm}$ e temperatura média de $20,6^{\circ} \mathrm{C}$. Na área de mata higrófila ocorre afloramento do lençol freático, limitando o número de espécies vegetais neste local. Foram utilizados para observações de visitantes florais seis indivíduos em pleno florescimento (18 inflorescências no total), próximos uns dos outros na margem de um pequeno córrego, em área brejosa.

Os visitantes foram registrados ao tocarem as inflorescências e iniciarem algum comportamento indicativo de coleta de recursos. As 18 inflorescências foram observadas simultaneamente. Foi utilizado o método 
de amostras fixas ${ }^{23}$ para fazer 24 horas de observações contínuas, com auxílio de binóculos, das $6 \mathrm{~h}$ às $18 \mathrm{~h}$, durante dois dias seguidos.

\section{RESULTADOS}

Duas espécies de beija-flores (Chlorostilbon aureoventris e Thalurania glaucopis) (Tabela 1) visitaram as inflorescências de Buddleja brasiliensis. Também foram visitantes florais os himenópteros Apis mellifera (Apidae), Tetragonisca angustula (Meliponinae), Exomalopis sp. e Plebeya droriana (Anthophoridae), Linepithema sp. (Formicidae) e uma borboleta Pieridae.

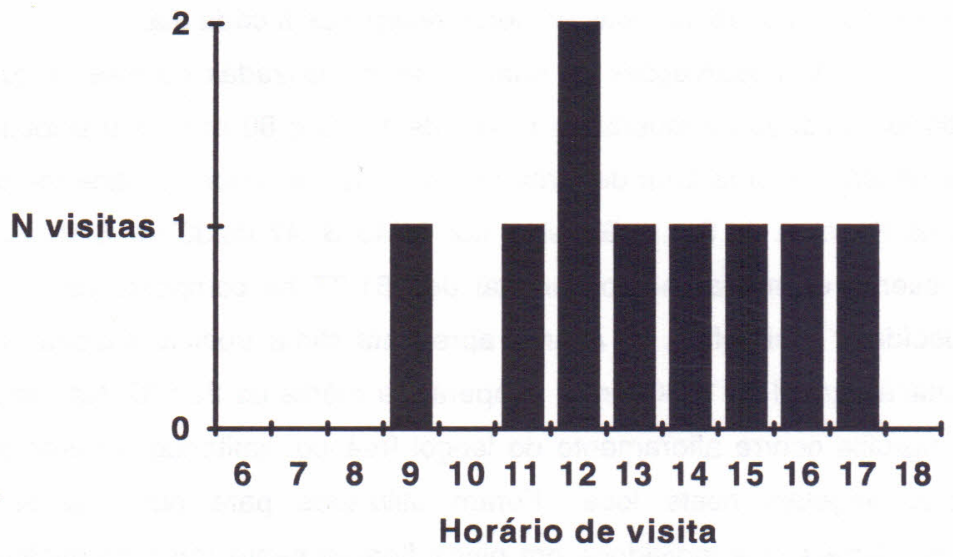

Figura 1. Freqüência de visitas de Chlorostilbon aureoventris a flores de Buddleja brasiliensis em mata semidecídua higrófila ( 24 h de observação).

O beija-flor-de-bico-vermelho (Chlorostilbon aureoventris) realizou visitas à partir das $9 \mathrm{~h}$, com pico às $12 \mathrm{~h}$ e intervalos entre visitas de 
aproximadamente uma hora (Figura 1). O beija-flor adeja a inflorescência, visita 3-8 flores e voa para longe das plantas. Em duas ocasiões este beijaflor visitou inflorescências de dois indivíduos diferentes. Cada visita ao agrupamento vegetal durava menos de $2 \mathrm{~min}$. O beija-flor-de-testa-azul (Thalurania glaucopis) realizou apenas uma visita, às $11 \mathrm{~h} 26 \mathrm{~min}$, e permaneceu próximo à planta. Após cerca de 1 min ocorreu uma interação agressiva intra-específica e ambos os indivíduos deixaram o local.

Apis mellifera e Exomalopis sp. pousavam nas inflorescências e procuraram ativamente por recursos. Estas abelhas apresentavam o comportamento de coleta de pólen assim como o de ingestão de néctar. As visitas da abelha melífera ocorreram à partir das $7 \mathrm{~h}$, se prolongando até às 18h, com pico de visitação entre $9 \mathrm{~h}$ e $10 \mathrm{~h}$ (Figura 2). As visitas de Exomalopis sp. começaram à partir das $9 \mathrm{~h}$ e cessaram entre $16 \mathrm{~h}$ e $17 \mathrm{~h}$, com pico de visitação às $12 \mathrm{~h}$ (Figura 2).

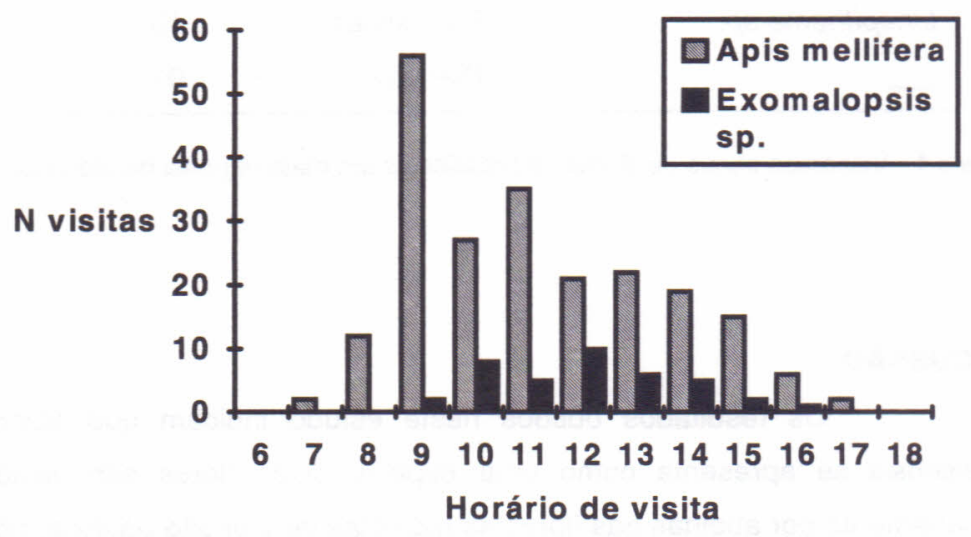

Figura 2. Freqüência de visitas de Apis mellifera e de Exomalopsis sp. a flores de Buddleja brasiliensis em mata semidecídua higrófila ( $24 \mathrm{~h}$ de observação). 
As demais espécies animais que forragearam nas inflorescências apresentaram freqüências de visitas muito baixas (Tabela 1). A formiga Linepithema $\mathrm{sp}$. foi o único visitante a não tocar anteras e estigmas, não sendo, portanto, considerado como potencial polinizador da planta.

\begin{tabular}{llc}
\hline \hline Visitantes & Família & № de visitas \\
\hline AVES & Trochilidae & 08 \\
$\begin{array}{l}\text { Chlorostilbon aureoventris } \\
\text { Thalurania glaucopis }\end{array}$ & Trochilidae & 01 \\
INSECTA & & \\
Apis mellifera & Apidae & 195 \\
Exomalopsis sp. & Anthophorida & 39 \\
& e & \\
Plebeya droriana & Anthophorida & 02 \\
& e & \\
Tetragonisca angustula & Apidae & 02 \\
Linepithema sp. & Formicidae & 10 \\
& Pieridae & 01 \\
\hline
\end{tabular}

Tabela 1 - Visitantes florais de Buddleja brasiliensis em mata higrófila de planalto.

\section{DISCUSSÃo}

Os resultados obtidos neste estudo indicam que Buddleja brasiliensis se apresenta como uma espécie cujas flores são visitadas primariamente por abelhas nas florestas higrófilas de planalto paulista, pois a freqüência de visitas de beija-flores é muito pequena. Estudos realizados em populações do vegetal que ocorriam acima de $900 \mathrm{~m}$ em Mata Atlântica no Estado de São Paulo mostraram que a visitação por beija-flores é muito mais significativa que a de insetos ${ }^{5,18}$. Chlorostilbon aureoventris, o beija-flor mais 
freqüente nas flores de $B$. brasiliensis, é um visitante floral oportunista, muitas vezes observado em jardins e pilhando néctar de flores ornitófilas $9,24,25$

A maior freqüência de abelhas nas flores de Buddleja brasiliensis em floresta higrófila de planalto, quando comparada a áreas montanhosas, pode ser devido à quase inexistência de abelhas em florestas de altitudes durante o inverno ${ }^{19}$. A baixa freqüência de visitas de beija-flores na Reserva de Santa Genebra também pode ser explicada pelo reduzido número de espécies e indivíduos de beija-flores nesta mata, com apenas três espécies residentes (Phaetornis pretrei, Amazilia lactea e T. glaucopis) ${ }^{24}$. Provavelmente a fragmentação das matas semidecíduas originais que ocorriam no planalto paulista concorreram para o depauperamento da avifauna nos fragmentos que restam ${ }^{26,27,28}$.

\section{AGRADECIMENTOS}

Agradeço I. Sazima por sugerir a realização do presente estudo, por valiosas discussões e por identificação das espécies de beijaflores, M. Sazima por auxiliar na identificação das espécies de abelhas e por discussões ao longo do estudo, P. S. Oliveira por identificação da espécie de formiga e J. Semir por confirmação da espécie vegetal. Agradeço também à Fundação José Pedro de Oliveira por permitir a realização do estudo na Reserva de Santa Genebra. Este artigo é dedicado ao Professor Hermógenes de Freitas Leitão-Filho, que partiu prematuramente. 
BAWA, K. S. Plant-pollinator interactions in tropical rain forests. Ann. Rev. Ecol. Syst., 21: 399-422. 1990.

GREENEWALT, C. H. Hummingbirds. New York: Dover Publications, Inc. 1990.

GRANTSAU, R. Os beija-flores do Brasil. Rio de Janeiro: Expressão e Cultura. 1988.

SNOW, D. W. \& SNOW, B. K. Relationships between hummingbirds and flowers in the Andes of Colombia. Bull. Brit. Mus. Nat. Hist. (Zool.), 38: 105-139. 1980.

SNOW, D. W. \& SNOW, B. K. Feeding ecology of hummingbirds in the Serra do Mar, southeastern Brazil. El Hornero, 12: 286-296. 1986.

SNOW, D. W. \&TEIXEIRA, D. L. Hummingbirds and their flowers in the coastal mountains of southeastern Brazil. J. Ornit., 123: 446-450. 1982.

SAZIMA, M. Hummingbird pollination of Barbacenia flava (Velloziaceae) in the Serra do Cipó, Minas Gerais, Brasil. Flora, 168: 239-247. 1977.

SAZIMA, M. \& MACHADO, I. C. S. Biologia floral de Mutisia coccinea St. Hil. (Asteraceae). Rev. Bras. Bot., ㅁ: 103-108. 1983.

SAZIMA, M. \& SAZIMA, I. Hummingbird pollination in two species of Vellozia (Liliiflorae: Velloziaceae) in southeastern Brazil. Bot. Acta, 103: 83-86. 1990.

SAZIMA, I.; BUZATO, S. \& SAZIMA, M. The saw-billed hermit Ramphodon naevius and its flowers in southeastern Brazil. J. Ornith., 136: 195-206. 1995.

ARAUJO, A. C. Beila-flores e seus recursos florais numa área de planície costeira do litoral norte de São Paulo. Dissertação de Mestrado. Universidade Estadual de Campinas. 1996.

FEISINGER, P. Coevolution and pollination. In: D. S. Futuyma \& M. Slatkin (eds.) Coevolution. Sinauer Press, Sunderland, pp. 282-310. 1983.

FRISCH, J. D. \& FRISCH, C. A. D. 0 jardim dos beija-flores. São Paulo: Dalgas-Ecoltec Ecologia Técnica. 1995.

FEINSINGER, P. \& CHAPLIN, R. K. On the relationship between wing disc loading and foraging strategy in hummingbirds. Am. Nat., 108: 217-224. 1975.

ARIZMENDI, M. DEL C. \& ORNELAS, J. F. Hummingbirds and their floral resources in a tropical dry forest in Mexico. Biotropica, 22: 172-180. 1990.

FIGUEIREDO, R. A. de \& ALVARES, S. Freqüência de visitas e comportamento alimentar do beija-flor Phaetornis pretrei nas flores de uma Cactaceae. Bioikos, 7: 28-33. 1993.

140 Rev. Ciência e Natura, Santa Maria, 19: 133 - 141, 1997 
WOLF, L. L., STILES, F. G. \& HAINSWORTH, F. R. Ecological organization of a tropical highland hummingbird community. J. Anim. Ecol., 32: 349379. 1976.

BUZATO, S. Estudo comparativo de flores polinizadas por beija-flores em três comunidades de Mata Atlântica no sudeste do Brasil. Tese de Doutorado.Universidade Estadual de Campinas. 1995.

SAZIMA, I.; BUZATO, S \& SAZIMA, M. An assemblage of hummingbirdpollinated flowers in a montane forest in southeastern Brazil. Bot. Acta, 109: 149-160. 1996.

JOLY, A. B. (1991) Botânica: introdução à taxonomia vegetal. São Paulo: Ed. Nacional. $10^{\text {a. }}$ ed., p.592. 1991.

LORENZI, H. \& SOUZA, H. M. Plantas ornamentais no Brasil. Nova Odessa: Ed. Plantarum. 1995.

MORELLATO, L. P. C. \& LEITÃO-FILHO, H. F. Ecologia e preservação de uma floresta tropical urbana: Reserva de Santa Genebra. Campinas: Ed. Unicamp. 1995.

DAFNI, A. Pollination ecology: a pratical approach. Oxford: IRL Press. p.166174. 1992.

SAZIMA, M. \& SAZIMA, I. Os beija-flores e suas flores. In: L. P. C. Morellato \& H. F. Leitão-Filho (eds.). Ecologia e preservação de uma floresta tropical urbana: Reserva de Santa Genebra. Campinas: Ed. Unicamp. p.60-63. 1995.

MITCHELL, M. H. Observations on birds of southeastern Brazil. Canada: University of Toronto Press. 1957.

ALEIXO, A. Aves da Mata de Santa Genebra: lições para a conservação de fragmentos florestais. In: L. P. C. Morellato \& H. F. Leitão-Filho (eds.). Ecologia e preservação de uma floresta tropical urbana: Reserva de Santa Genebra. Campinas: Ed. Unicamp, p.83-86. 1995.

MARINI, M. A. Menos matas, menos pássaros. Ciência Hoje, 20: 16-17. 1996.

WILLIS, E. O. \& ONIKI, Y. Levantamento preliminar de aves em treze áreas do estado de São Paulo. Rev. Bras. Biol., 41: 121-135. 1981. 
142 Rev. Ciência e Natura, Santa Maria, 19: 133 - 141, 1997 